\title{
The Spectator Fulfilling the Concept of Liveness
}

\author{
Huan Fan \\ Sichuan University \\ Chengdu, China \\ crisly@foxmail.com
}

\section{INTRODUCTION}

In principle, the abstract idea of liveness carried in a work has always been genuine. It is genuineness that makes the spectators totally believe which circumstance they are actually in even at a distance. However, for Walter Benjamin, the genuineness of the thing is a "supremely sensitive core (Benjamin 2008) that cannot be replaced by the medium of reproduction and is not capable of being resurrected by any manual or technological means. With the course of time, technology has made it possible for the spectator to experience some live moments again and again. Such feeling is living within a situation and mostly needs to be actualised by the electric and high-tech applied on the artworks. This dialectically proves that the relationship between the creator and the spectator is interactive though the medium of works, which henceforth lies with the spectator alone when they just participate in that work, which is designed by artists and substitutes for the work's "unique incidence a multiplicity of incidences" (Benjamin 2008) during the process of the experience.

\section{IGNORANCE}

In the famous piano work 4'33" played by John Cage (1952), which was silent throughout three parts except for some minute noise of the watch and the movement of closing the piano lid, there is no doubt that the audience was tricked by the artist. One new spiritual search from Zen Buddhism philosophy hits on the idea to create that phenomenon. It includes the inspiration for changes so that everything which surrounds you can be seen as the whole music performance not just the one being played on the stage. It also includes the changes to the spectators' entertainment happening in the theatre or hall, where those changes are not merely a particular instance as in avant-garde art, but also a step forward into the viewer's field.
Such ignorance with silence is something that forces the spectator to involve themselves in the challenge and invitation of the artwork. The reason is twofold. In the first place, anticipation of the work of art as it occurs historically has been challenged over the course of time. All of the master's artwork is constituted and organised with the aim of goodness and quiet grandeur. No one suspected that rule and it forces the works to start from the feeling of amusement of the spectator. Therefore, Plato (1958, back cover) "banishes art from his city" because that art is characterised by amusement. That enjoyable amusement will make the audience indulge themselves in it and damage the stable pace of development of their civilization. By contrast, in modern life, the financial gain has caused that amusement to become so popular as to forget the spiritual pursuit of art, which it has always been. If the anticipation of amusement has been damaged, the viewer will be in a new stage which means rethinking the meaning of art again. Secondly, it can be seen as a profound trick from the creator. Those feelings were observed and described by the sensitive critic Michael Fried. He realised that the experience of the spectator is not as previously, within the artworks itself, but "the actual circumstances in which the beholder encounters literalist work (Fried 1995). In other words, it is "an object in a situation... [and]...includes the beholder (Fried 1995). Moreover, Minimalism using the large scale to constantly repeat the works, even in "one's body size (Fried 1995), "apprehends the object from various positions and under varying conditions of light and spatial context" (Fried 1995) to form theatricality in order to attract the spectator. To affect the beholders' sense is so enormously true, like being on a stage within a closed room. This illustration happened without interesting story plots or seats to relax in. Above all, the ignorance from the creator is a recall for more attention and participation in the artworks, not only in body but also in mind. 


\section{INTERACTION}

With the development of technology, the process of interaction in the work of art has been acceptable and tolerated by most of the spectators. The very much freer process represented by releasing the right to the viewer to do whatever they want, allows them to find a place for their behaviour among the process of presenting. It becomes vital to actualise the concept of the artwork in comparison with the original, which in the past has had the everlasting value of being respected by the public.

Nam June Paik, another particularly important artist who followed Cage to create artworks but move further than him, tries to reveal and explore the meaning of interaction in its process and result. Using the magnet to transform the shape of graphic art on television, sometimes it shows a situation of the leader of a powerful country at that moment making a speech. The things the spectator is allowed to do, such as using the magnet or axe to cause damage to the television, change the image inside. So far as the process is concerned, uncontrolled things will happen beyond the normal imagination.

That "spectator 'participation', theorised by Fluxus happenings and performances, has become a constant feature of artistic practice" (Bourriaud 2002). Within the process of interaction, the receiver's field is also "a forever unfinished discursiveness (Bourriaud 2002). Drawing the attention of the viewer can bring a social ambition into the artworks, which leads to the prosperity of interactive art. At the same time, the content and the technology of the artworks divides into two different paths. Some merely focus on how to apply high-tech and not care about the value of art. Others have much more interesting design based in cultural heritage, which can be understood to create for contents' sake. The former can only be seen as a show of developing technology that cannot carry out the meaning of art, while the latter includes more possibility of aesthetic thinking

\section{INCIDENCE}

Duchamp's notion that "it's the beholder who make pictures gives full trust in the spectator. Nicolas Bourriaud (2002 p.26) also points out that "to describe the specific nature of present-day art with the help of the concept of crating relations outside the field of art, .... relations ...., and, by way of transitivity, between the beholder and the world. (Bourriaud 2002) The viewer will constitute the system of art criticism. The relationship between the art and the public is opposed to the core of elite art. The incidence here refers to the possibility of the uncontrolled mind and behaviour. What you cannot reach is the power to reach the truth and the end.

In Nicolas Bourriaud's (2002 p.26) view, "the 'society of the spectacle' is thus followed by the society of extras, where everyone finds the illusion of an interactive democracy in more or less truncated channels of communication." Technology has changed the perception of the human eye, and also changed the way of communication. That illusion for the spectators may be a misunderstanding of a different time, space, culture and personal backgrounds. Some artists notice this new misunderstand, therefore they also design for their work with an open ending via the computer procedure. The movement of touching the artwork will be record and arbitrarily recombined by computer to create the result. The process of interaction may inspire the next step of the creator, pushing him to find an unknown field.

\section{REFERENCES}

Benjamin, W. (2008) The Work of Art in the Age of Mechanical Reproduction. Penguin Books, England.

Bourriaud, N. (2002) Relational Aesthetics. Les presses du, F. Dijon.

Collingwood, R. G. (1958) The Principles of Art. Oxford University Press, Oxford.

Fried, M. (1995) Minimal Art: A Critical Anthology. University of California Press, Berkeley. 